very great advantages in its favour; and, for all laboratories supplied with aqueduct-pressure, I venture to think that it affords the best solution of the problem of inexpensive, convenient, and effective power.

Lawrence Observatory, Amherst, Mass., May I5

\section{Scientific Nomenclature}

In a letter published in Nature for May 27 (p. 76) Prof. Minchin proposes to replace the expression "potential energy" by "static energy." It seems to have escaped his notice that a similar expression, proposed many years ago by Sir William $\mathrm{Th}$ mson, was used until it was replaced by the very words which Prof. Minchin wishes now to abolish. A short account of the question is given by Maxwell in "Matter and Motion," p. $8 \mathrm{I}$, and I should like to bring the following passage to the notice of those who take an interest in this question :-

"This is called the 'sum of the tensions' by Helmholtz in his celebrated memoir on the 'Conservation of Energy.' Thomson called it statical energy ; it has also been called energy of position; but Rankine introduced the term potential energy-a very felicitous expression, since it not only signifies the energy which the system has not in actual possession but only has the power to acquire, but it also indicates its connection with what has been called (on other grounds) the potential function."

Harrow, June 8

G, GRIFFITH

\section{Ntæra}

I wish to request any of your readers who may dredge, or have opportunity this summer, to observe living or fresh specimens of the genus Neara, Gray, and see whether branchiæ exist in that group. A Lamellibranch without branchiæ is anomalous, to say the least. I find in a new species of Necera (sub-genus Myonera) from the Gulf of Mexico the following anatomical facts :- The mantle closed except for the small siphon and a narrow short slit for the thorn-shaped foot; no gills, no palps; the oral opening circular, plain ; the roof of the peripedal cavity between the base of the body and the mantle margin is flattish, fleshy, with sparse pustules; a peripheral very stout pink muscle runs on each side around this, and is prolonged upward to the shell before the true adductor at each end of each valve, thus accounting for the double scars to be found there; the foot is close to the oral orifice, not grooved for the by-sus, but pedunculated and surrounded by a groove; around the siphonal opening are numerous tentacular processes and a moderate number of ocelli. The specimens appear to be adult and perfectly preserved. An examination of specimens of Ncara arctica and Neera obesa, Lovèn, indicated a similar state of affairs, though these specimens were not in as good condition as the one from the Gulf of Mexico. I do not find in the literature any categorical statement of the observation of gills in this genus. Clark is non-committal (in his "British Testacea"), Jeffreys speaks of seeing the "pink gills" through the shell, but that which he saw pink was without doubt the circular muscle I have mentioned.

The question is worthy of a definite solution. My specimens seem to leave no doubt that there are no gills, but it is always best to be suspicious of material long in alcohol.

WM. H, DALL

Smithsonian Institution, Washington, D.C., May 27

\section{"Plants and their Defences"}

WITH regard to the interesting article in your issue for May 6 (p. 5) on "Plants and their Defences," I should like to offer two remarks, and in return would be very glad to receive from you information upon a certain pjint. (I) The author enumerates different species of plants protected by the severe stings of ants, but d ses not seem to know the remarkable work of Beccari, "Piante ospitatrici ossia piante formicarie della Malesia e della Papuasia" (Malesia, vol. ii., Firenze, I885). Beccari describes seventeen partly new species of "Myrmecophilous" Rubiaceæ, among which are eleven of Hydnophytum (not Hydriophytum, as is erroneously given in the article in NATURE). You will find a further contribution to this question in Henry $O$. Forbes's "Wanderungen durch den Malayischen Archipel," vol. i. pp. $84-88$ of the German translation.

For my part, I should be greatly obliged if you would communicate to me the title of the original nork from which the author of "Plants and their Defences" has taken his account of Triplaris Schomburgkiana, Schomburgkia tibicinis, and Acacia spharocephala.

(2) Concerning the same article, Mr. Alfred W. Bennett (NATURE of May 20, p. 52) is inclined to think that the poisonous fluid of the nettle-glands is not formic acid, as generally conjectured, because the fluid frequently has an alkaline reaction. As a matter of fact, Prof. Dr. Haberlandt, at Graz (Austria), has recently, in vol. xciii. of Sitzungsberichte des kaisen l. Akademie d:r Wissenschaften in Wien, 1886, FebruarHeft, shown in his article, "Zur Anatomie und Physiologie der pllanzlichen Brennhaare," that (I) the poison of the stinging glands is not identical with formic acid; (2) $n>r$ is it the albumen dissolved in the fluid of the glands; but (3) that most probably this fluid is a transformed ferment or enzymotic poison.

Frankfurt a. Oder, June 2

E. HuTH

\section{A Remarkable Hailstorm}

ON April I 7, at 4 o'clock p.m. (local time), a very remarkable hailstorm visited the neighbourhood of a smail hamlet, called El Totumo, ${ }^{1}$ not far from the town of Tinaco, section Cojedes, State of Zamora, Venezuela. The place is approximately in $9^{\circ}$ $25^{\prime} \mathrm{N}$. lat., and $68^{\circ} 5^{\prime}$ long. W. of Greenwich, certainly not more than 200 metres above sea-level. My informant is a resident of El Totumo, named Nicolas Moreno Nuñez, who is universally said to be a trustworthy and respectable man. There was first a very heavy thunderstorm with much rain; but after some time hailstones began to fall in such abundance that it might have been easy to collect them by hundreds of bushels, some weighing as much as two ounces. It is well known that between the tropics hailstorms are exceedingly rare in localities situated in the lowlands; but the present case is still more interesting, on account of the colour of the hailstones, some of which were whitish, whilsi others were blue or rose-coloured. I have read of but one instance in which the two last-mentioned colours were observed, viz. in the hailstorm of Minsk of June I4, 1880, described by Lagunowitch, and quoted by Th. Schwedoff in his memoir "On the Origin of Hailstorms." 2 Schwedoff thinks that the blue and rosy colours are owing to the presence of salts of cobalt and nickel, and thus confirm his hypothesis of the cosmic origin of hal. I do not know whether the existence of those mineral constituents in the hailstones of Minsk was ever made certain by chemical analysis, and it is of course impossible for me to do so in the present case, when almost a month has passed since the phenomenon took place. But it is undoubtedly a very curious coincidence that tl.e same colours should have been observed in both instances and in localities so widely separated from each other; whilst there is not the slightest possibility that my informant, an honest and plain countryman of no literary education whatever, should have had any know. ledge of such an observation having been made before. Caracas University, May 12

A. ERNST

\section{VISITATIO.V OF THE ROYAL OBSERVATORY}

THE visitation to the Royal Observatory by the Board of Visitors took place last Saturday, when there was a very numerous attendance. The report of the Astronomer-Royal to the Board gives, as usual, an account of the work done during the past year, and references to any points of interest or importance which have been raised. From the report we select the following particulars :-

Mr. Turner has recently investigated the discordance between observations for coincidence of the collimators made respectively through the apertures in the cube of the transit-circle and with the instrument raised. A wooden model of the cube was constructed through which the observation could be made when the transit-circle was raised, and it was thus shown that the discordance was due to the cutting off of portions of the object-glasses by the cube, and not to any effect of tem, erature. In view of this result it seems desirable that the optical

This is the vernacular name of the calabash-tree (Crescen:ia Cujete); there is, or was, probably a remarkable sfecimen of this tree in the neighbourh od of the hamlet.

I only know a Spanish translation of Schwedoff's memoir, in Crónica cien:ifica (Barcelona), 1882, No. 120, pp. 553-60. 
definition of the collimator object-glasses should be thoroughly tested.

A discussion of the collimation-observations made throughout the year 1885 with the reversion-prism shows that for the regular observers the personality depending on the apparent direction of measurement is extremely small. Any possible effect of the kind is eliminated by the method of observation adopted with the reversionprism. The personality depending on the direction of motion, as deduced from the results of reversed and ordinary transits of clock-stars with the reversion-prism, appears to be more decided, though the amount is small except in the case of one observer.

The personal equation instrument was completed last autumn, but was dismounted during the winter to preserve it from injury in the bad weather. Series of observations have been taken with it on five days, and the results appear to be very satisfactory, the accordance being as close as could be expected. The absolute personal equations thus obtained seem to show that all the observers observe too late, the differences between the several observers agreeing well with the relative personal equations found from observations of clock-stars.

The sun, moon, planets, and fundamental stars have been regularly observed during the past year, together with other stars from a working catalogue containing about 2750 stars. Good progress has been made in the observation of these stars, in view of the formation at the end of I 886 of a Ten-Year Catalogue, epoch $1830^{\circ}$. The annual catalogue of stars observed in 1885 contains about I 250 stars.

The following statement shows the number of observations made with the transit-circle in the twelve months ending I886 May 20 :-

Transits, the separate limbs heing counted as separate observations

Determinations of collination error $\begin{array}{lllll}\cdots & \cdots & \cdots & 5685\end{array}$

$\begin{array}{llllllr}\text { Circle observations } & \ldots & \ldots & \ldots & \ldots & \ldots & 332 \\ \end{array}$

Determinations of nadir point (included in the number of c rele-observations)

Reflection-observati ns of stars (similarly included)

The value found for the co-latitude from the observations of 1885 is $38^{\circ} 31^{\prime} 22^{\prime \prime} \cdot 0$. , differing by $0^{\prime \prime} 14$ from the assumed value ; the correction to the tabular obliquity of the ecliptic is $+\mathrm{O}^{\prime \prime} \cdot 8 \mathrm{I}$; and the discordance between the results from the summer and winter solstices is $-0^{\prime \prime} 9^{8}$, indicating that the mean of the observed distances from the pole to the ecliptic is too great by $+0^{\prime \prime} 49$.

The mean error of the moon's tabular place (computed from Hansen's Lunar Tables with Prof. Newcomb's corrections) is + 0.02s. in R.A. and $+0^{\prime \prime} \cdot 36$ in longitude, as deduced from 105 meridian observations in 1885 . The mean error in tabular N.P.D. is $-0^{\prime \prime} \cdot 58$, which would appear to agree with the observations of the sun in indicating that the mean of the observed N.P.D.'s is too great.

The observations of the moon with the altazimuth have, as usual, been restricted to the period from last quarter to first quarter in each lunation, the total number of observations of various kinds made in the twelve months ending 1886 May 20 being as follows :-

$\begin{array}{lllll}\text { Azimuths of the moon and stars } & \ldots & \ldots & \ldots & \text { 213 } \\ \text { Azimuths of the aziinuth-mark } \ldots & \ldots & \ldots & \text { I46 } \\ \text { Azimuths of the collimating-nark } & \ldots & \ldots & \text { 176 } \\ \text { Zenith-distances of the moon } & \ldots & \ldots & \ldots & \text { I IO } \\ \text { Zenith-distances of the collimating-mark } & \ldots & \text { I72 }\end{array}$

The reversion-prism has been used during the past year with the altazimuth for investigation of the personality depending on the apparent direction of motion of stars or the moon. The plan adopted bas been to observe a transit over the first three wires with a certain apparent direction of motion and over the last three with the apparent direction of motion changed. A second transit is then observed with the conditions reversed, so that in each double transit there are two sets of observations over the same six wires with the apparent direction of motion different, from which a determination of the personality is obtained by simple subtraction without any calculation of intervals of wires. The results show that the personality is in every case small, and that further observations are required to separate it from accidental errors of observation.

A cloc's synchronised by hourly currents, on Lund's system, has been presented to the Observatory by the Standard Time and Telephone Company, and is fixed in the Astronomer-Royal's office.

A new plane mirror (silver on glass) has been obtained from Mr. Calver for the Lassell equatorial, and a wooden screen has been fixed at the eye-end to protect the open end of the tube from the heat of the observer's body, it having been found that the definition was much affected by convection-currents at the eye-end, giving rise to an apparent astig natism which was at first supposed to be caused by tilt of the large mirror. The optical performance appears now to be satisfactory. At Mr. Common's suggestion a frictional connection between the clock and the driving-screw has been applied so as to allow of the latter being turned in either direction (for slow motion in R.A.) without putting the clock out of gear.

For determination of motions of stars in the line of sight, 378 measures have been made of the displacement of the $F$ line in the spectra of $5 \mathrm{I}$ stars, and $2 \mathrm{I}$ measures of the $b$ lines in 8 stars, besides measures of the displacements of the $b$ and $F$ lines in the spectra of Mars and Venus, and of the east and west limbs of Jupiter, and comparisons with lines in the spectrum of the moon, or of the sky, made in the course of each night's observations of star-motions, or on the following morning, as a check on the general accuracy of the results. The observations of Sirius during the past twelve months indicate, as in the last three jears, a displacement of the $\mathrm{F}$ line towards the blue (corresponding to a motion of approach), the amount being siightly larger than in the preceding year. Spectroscopic observations were interrupted on a number of night; through deficient supply of water for the driving-clock of the south-east equatorial. After some correspondence with the Kent Waterworks Company it was arranged that the pressure in the Observatory main should not be reduced to so low a point in the evening, and no further trouble with the water supply has been experienced since. The experiments with the reversion spectro: cope of the Oxford University Observatory (lent by Prof. Pritchard) indicate that this form of instru nent is well adapted for observation of displacements, provide 1 certain improvements can be effected in the optical and mechanical parts.

For the year I885 Greenwich photographs are available for measurement on 208 days, and photographs from India and the Mauritius, filling up the gaps in the series, on 152 days, making a total of 360 days out of 365 on which photographs have been measured. The record has thus been made practically complete for 1885 by means of the Indian and Mauritius photographs.

A table of the means of daily areas of spots and faculæe and of th = mean heliographic latitude of spots has been formed for each synodic rotation of the sun, and for each year from the commencement of the Greenwich series in I 873 to the end of 1885 .

Further experiments for determination of the temperature corrections for the horizontal and vertical force magnets by alternately warming and cooling the basement on successive days were made in the spring of this year, a continuous record of the temperature being obtained by means of the Richard thermograph. The following are the results thus obtained in 1885 and 1886 as compared with the previous determinations, the appa- 
rent changes for $\mathrm{I}^{\circ}$ of temperature being expressed in terms of the horizontal force and vertical force respectively :-

For $x^{\circ} \mathrm{Fahr}$. increase of temperature Apparent decrease of horizontal force

$\begin{array}{ccc}1868 & 1885 & 1886 \\ .00018 & 00026 & 00021 \\ 1882 & 1885 & 1886 \\ .00020 & 00022 & 00020\end{array}$

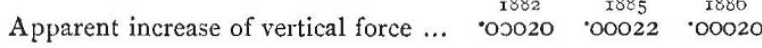

The following are the principal results for magnetic elements for I 885 :-

Approximate mean declination $18^{\circ} 2^{\prime}$ west.

Mean horizontal force... $\quad \ldots\left\{\begin{array}{l}3.9376 \text { (in English units). } \\ 3.8156 \text { (in metric units). }\end{array}\right.$

Mean dip $\quad \ldots \quad \ldots \quad \ldots\left\{\begin{array}{lll}67 & 27 & 28 \text { (by } 9 \text {-inch needles). } \\ 67 & 27 & 32 \text { (by } 6 \text { inch needles). }\end{array}\right.$

$\left\{\begin{array}{lll}67 & 27 & 32 \text { (by } 6 \text { inch needles). } \\ 67 & 28 & 27 \text { (by } 3 \text {-inch needles). }\end{array}\right.$

In the year 1885 there were only three days of great magnetic disturbance, but there were also about twenty days of lesser disturbance for which it may be desirable to publish tracings of the photographic curves. It is proposed to add tracings of the registers on four quiet days to serve as types of the ordinary diurnal movement at four seasons of the year, as was done for I 884 .

The automatic drop of the Greenwich time-ball failed on two days during the past twelve months, on one occasion through accumulation of snow on the mast, and on another through failure in the clock-work apparatus for daily reversal of the currents through the electro-magnets. This apparatus has since been removed, and the direction of the currents is now reversed by hand once a week. On one day the ball was not raised on account of the violence of the wind.

As regards the Deal time-ball, there have been seven cases of failure owing to interruption of the telegraphic connections, and on three days the violence of the wind prevented the raising of the ball. There have been three cases of failure of the I p.m. signal to the Post Office.

No further action has been taken as regards the establishment of hourly time-signals at the Lizard or Start, as the arrangements for preliminary trial of a collapsible cone at Devonport are not yet completed. One of the Transit of Venus clocks (Dent 20Io) has been adapted by Messrs. E. Dent and Co. to give hourly time-signals, and to be synchronised by the help of an auxiliary seconds' pendulum on the plan I proposed in the last report.

The longitude of Gibraltar was determined last year under Capt. Wharton's direction, by exchange of telegraphic signals on August 8, 9, and 12 between Greenwich and Gibraltar, the Eastern Telegraph Co. having courteously given the free use of their telegraph cable for the purpose. The signals were transmitted by relayaction from the ends of the cable to the observing-stations at Greenwich and Gibraltar. Local time was determined at Gibraltar by the officers of H.M.S. Sylvia with the sextant, and at Greenwich by Commander Moore and Lieut. Douglas by means of sextant observations, and also by transits with the transit-circle. In connection with this determination a large number of observations of signals were made at Greenwich for the determination of the personal equations of the different observers in observing telegraph signals. At Greenwich the longitude signals were observed by five observers independently. Commander Moore and Lieut. Douglas made a series of observations at Greenwich last summer for comparison of the relative value of determinations of local time made with a sextant and with a small transit instrument respectively.

The record of the past year shows that the work in all branches tends to increase. This increase could not well be resisted without impairing the efficiency of the Observatory, but year by year it causes more pressure on our limited staff, which, in addition to scientific work, is charged with the ever-increasing duties of a Government Office. In this connection I may mention that a good deal of my own time, as well as that of the Chief Assistant, has lately been occupied with various matters connected with the Navy, reference having been made to me on the subject of gun-directors, mirrors for electric search-lights, and binoculars, in all of which there are involved questions requiring careful consideration.

Commencing with the year 1885, Greenwich civil time, reckoning from midnight to midnight and counting from 0 to 24 hours, has been adopted in the spectroscopic and photographic results as well as in the magnetical and meteorological. It is proposed to defer the introduction of this time-reckoning into the astronomical results till the year I89I, for which year the Board of Visitors have recommended its adoption in the Nautical Almanac. In an Observatory such as this, where observations of various classes are carried on, there is, however, considerable inconvenience in the retention of the present astronomical day, which now involves the use of two systems of reckoning mean solar time in the same establishment.

The construction of an object-glass of 28 inches aperture and of 28 feet focal length, with suitable tube, to be mounted on the south-east equatorial, has been authorised by the Government, and the necessary funds have been provided in the estimates. The work has been intrusted to $\mathrm{Mr}$. Grubb, with whom I have arranged the details of the tube, which is to be of special construction, adapted to the conditions of the mounting, and available for spectroscopy and photography as well as for eye-observations. Mr. Grubb proposes to provide means for readily separating the lenses of the object-glass to such a distance as will give the proper correction for photographic rays. Messrs. Chance are engaged in the manufacture of the glass for the lenses, and have already made a flint disk which promises to be very satisfactory.

In view of the recent development of astronomical photography, I propose to have constructed, for use with the present $12 \frac{3}{4}$-inch refractor of the south-east equatorial, a combination of a convex flint and concave crown lens, which, when placed about 2 feet within the focus, would correct the chromatic aberration of the object-glass for the photographic rays without alteration of the focal length. If this plan succeeds, the instrument would then be well adapted for photography, thanks to the firmness of its mounting and the excellence of its driving-clock.

\section{THE PAST WINTER}

$A T$ the meeting of the Royal Meteorological Society held on May I9 a paper was read on "The Severe Weather of the Past Winter, I $885-86$," by Mr. C. Harding, F.R.Met.Soc. The paper dealt with the six months from October to March in a general way, and with the three months from January to March more in detail, as the latter embraced the period during which the weather was most severe, and in which both frost and snow were exceptionally prevalent. The material used in the discussion was for the most part contributed by the kindness of the Meteorological Council.

The greatest deficiency of temperature throughout the winter occurred in the weeks ending January 25, March I, 8 , and $\mathrm{I}_{5}$, the defect on the average amounting to as much as $9^{\circ}$ and $10^{\circ}$ over the greater part of England. During the fortnight ending March 15 the mean temperature was below the freezing-point in the Midland Counties and in the north-west of England, and, considering the British Islands as a whole, the temperature was lower during this fortnight than in any similar period of the winter. The means for each of the six winter months show that the temperature was below the average over the whole Kingdom in October, January, February, and March. In the east, south, north-west, and south-west of England, and the Channel Islands, as well as over the 